ABDI: Jurnal Pengabdian dan Pemberdayaan Masyarakat ISSN: 2656-369X (Print), 2684-8570 (Online)

Volume 3 No. 2, Desember 2021

http://abdi.ppj.unp.ac.id/index.php/abdi

Email: abdi@ppj.unp.ac.id

DOI: https://doi.org/10.24036/abdi.v3i2.112

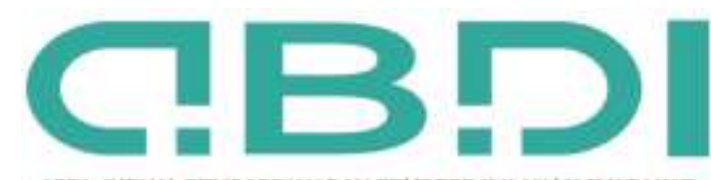

\title{
Pendampingan BIR (Bina Iman Remaja) dalam Tugas dan Fungsi BIR Sebagai Putera- Puteri Altar dengan Metode Dinamika Kelompok di Paroki Santo Fransiskus Asissi Padang Bulan Medan
}

\author{
Regina Sipayung \\ Prodi Pendidikan Guru Sekolah Dasar, Universitas Katolik Santo Thomas Medan \\ E-mail: sipayungregina1@gmail.com
}

\begin{abstract}
Abstrak
Usia remaja membutuhkan pengakuan yang kuat agar diterima dan disukai teman suusianya maupun kelompoknya. Dalam mengembangkan potensinya, remaja membutuhkan lingkungan yang dapat mendukungnya secara positif. Oleh karena itu, gereja katolik mencoba menangkap ini sebagai peluang untuk wadah para remaja berkumpul yang disebut dengan kelompok BIR (Bina Iman Remaja). Tujuan dari penelitian ini adalah untuk mengetahui apakah metode dinamika kelompok dapat diterapakan dalam mendampingi para remaja (BIR), apakah metode dinamika kelompok sesuai dengan tingkat perkembangan para remaja dalam mendampingi mereka akan tugas dan fungsi mereka sebagai putera-puteri altar di gereja Santo Fransiskus Assisi Padang Bulan Medan. Dari kegiatan pembinaan diperoleh hasil bahwa: a) Peserta dapat mengerti maksud yang disampaiakan dalam pelaksaaan pengabdian hal itu dapat dilihat dari antusias para peserta yaitu anggota BIR dan para pendamping BIR, b) Anggota BIR di gereja katolik Santo Fransiskus Assisi Padang Bulan Medan menyadari akan tugas dan fungsi mereka sebagai putera-puteri altar, c) Anggota BIR di gereja katolik Santo Fransiskus Assisi Padang Bulan Medan masih jarang menerima pengajaran, penyuluhan dan pelatihan metode dinamika kelompok, dan d) Para pendamping berkesempatan mengembangkan pengetahuannya melalui metode dinamika kelompok yang dapat semakin memberikan kesadaran kepada peserta akan tugas dan fungsi mereka sebagai putera-puteri altar.

Kata kunci: Altar, Bina Iman Remaja, Dimanika Kelompok

\section{Abstract}

Adolescents have a strong need to be liked and accepted by peers or groups. Teens need an environment that can develop their full potential and is positive. Therefore, the Catholic Church tries to capture this as an opportunity for youths to gather, which is called the BIR (Bina Iman Remaja) group. The purpose of this research is to find out whether the group dynamics method can be applied in accompanying adolescents (BIR), whether the group dynamics method is in accordance with the level of development of adolescents in accompanying them on their duties and functions as altar boys in the church of St. Francis Assisi, Padang. Medan month. From the coaching activities, the results show that: a) Participants can understand the meaning conveyed in the implementation of this service, it can be seen from the enthusiasm of the participants, namely BIR members and BIR assistants, b) BIR members at the St. Francis Assisi Catholic Church in Padang Bulan Medan are aware of their duties. and their functions as altar boys, c) BIR members at the Catholic Church of St. Francis of Assisi Padang Bulan Medan still rarely receive teaching, counseling and training in group dynamics methods, and d) Facilitators have the opportunity to develop their knowledge through group dynamics methods that can further provide awareness of the participants of their duties and functions as sons and daughters of the altar.
\end{abstract}

Key Word: Altar, Group Dynamics, Youth Faith Building,

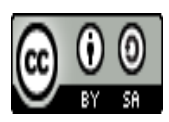




\section{Pendahuluan}

Bina Iman Remaja (BIR) adalah sebutan khas bagi anak usia remaja dalam gereja Katolik. Istilah BIR ini sejalan dengan apa yang disebut oleh Santrock (1904) dalam (Tibo, 2019), masa remaja yang usianya berkisar antara 12 hingga 23 tahun diwarnai oleh pergolakan. Pandangan badai dan stres (storm and stress view) yang menyatakan bahwa remaja merupakan masa pergolakan yang dipenuhi oleh konflik dan perubahan suasana hati. Pikiran serta perasaan dari masing-masing remaja selalu berubah. Kadang sombong, rendah hati, tergoda dengan hal buruk. Pikiran dan perasaan yang mereka alami, tidak bisa diduga penyebabnya, bahkan mereka sendiri tidak mengetahui mengapa mereka kadang merasa bahagia dan juga di saat yang tak terduga bisa juga merasa kesepian yang tiada tara (Hidayati, 2016).

Apabila remaja dalam masa mencari jati dirinya tidak memperoleh pengalaman baik, maka kemungkinan dia akan terpengaruh oleh lingkungannya. Jika lingkungannya baik maka dia akan baik, jika lingkungannya buruk, maka dia akan ikut buruk. Lingkungan yang salah juga membawa pengaruh yang buruk untuk perkembangan kepribadian remaja (Fatmawaty, 2017). Maka melalui organisasi dapat menjembatani remaja memenuhi kebutuhan perkembangan potensinya secara optimal. Menyadari hal di atas gereja katolik membentuk suatu wadah "keagamaan" yang menjadi tempat atau ruang yang positif dalam pengembangan kepribadian seorang remaja. Organisasi Gereja akan menjadi tempat bagi remaja untuk medapatkan pengalaman baik dan posistif.

Kegiatan BIR ini, bukan hanya hal-hal yang rohani saja, akan tetapi ada kegiatan kunjungan ke panti asuhan, minum kompi sama-sama dan berbagai kegiatan yang disesuaikan dengan kondisi remaja. Oleh karena itu pengabdian masyarakat yang dilakukan adalah mendampingi anak-anak BIR agar menyadari Tugas dan Fungsi Mereka sebagai Putera-Puteri Altar dalam gereja Katolik (Wanda et al., 2017). Mereka adalah pelayan-pelayan gereja katolik dalam melayani di altar Tuhan. Kegiatan BIR dilihat sebagai sebuah wadah perpanjangan tangan Gereja Katolik dalam melayani Tuhan dan mewartakan kasih dan kemurahanNya pada anak-anak melalui pembinaan iman anak sejak dini (Ramos \& Firmanto, 2017). Bagian terpenting dari semua aktivitas pembinaan iman anak adalah tujuannya yakni supaya anak semakin sadar dan mau menerima Yesus sebagai Tuhan dan Juru Selamat pribadinya. Dengan demikian, Bina Iman Remaja (BIR) dapat diartikan sebagai suatu wadah pelayanan dari, oleh, dan untuk Gereja yang bergerak dalam pelayanan iman bagi anak-anak usia dini (Wetu, 2017). Pembinaan iman yang dilakukan merupakan sebuah proses bantuan rohani yang diberikan secara sadar dan sengaja oleh orang dewasa sebagai pendamping iman anak sampai anak berusia 12 tahun. Tujuan dari pembinaan iman ini ialah supaya anak mengalami pertumbuhan dan perkembangan iman serta pembaharuan sikap hidup melalui penyerahan diri kepada Allah melalui Yesus Kristus dalam Gereja Katolik (Marbun, 2020). Pada usia dini, anak-anak pada umumnya masih menggantungkan diri pada orang dewasa dan memerlukan pembinaan supaya imannya tumbuh dan berkembang. Bina Iman Remaja (BIR) dipandang sebagai sebuah wadah pendidikan iman anak usia dini dan dapat membantu anak untuk mengenal dirinya secara utuh dan menyeluruh, mengenal hakekat panggilannya sebagai anggota Gereja, dan tugas perutusannya di dalam hidup sosial (Lating, 2016).

\section{Metode Pelaksanaan}

Kegiatan penyuluhan dan pelaksanaan program-program pengabdian pada masyarakat menjadi dilakukan secara langsung sebagai orientasi dari Lembaga Pengabdian Masyarakat (LP3M) Universitas Katolik Santo Thomas Medan. Program yang dipandang penting untuk dilaksanakan adalah dengan mengembangkan pengetahuan pemahaman anak usia Remaja akan Tugas dan Fungsi sebagai Putera-Puteri Altar dengan Metode Dinamika Kelompok. Metode ini digunakan untuk pengembangan emosionalnya; Memberikan motivasi dalam menjalani kehidupan beriman; Membangun rasa cinta kasih dan tanggung jawab terhadap lingkungan masyarakat khsususnya gereja sesuai dengan kemampuan dan usia perkembangan mereka. 
Untuk mengetahui metode dinamika kelompok dapat diterapakan dalam mendampingi para remaja (BIR) dalam mendampingi mereka akan tugas dan fungsi mereka sebagai putera-puteri altar di gereja Santo Fransiskus Assisi Padang Bulan Medan adalah:

\subsection{Persiapan}

Persiapan BIR dimulai dengan mengumpulkan anggota BIR dengan tetap mengikuti protokol kesehatan yang ditentukan pemerintah yaitu menggunakan masker, mencuci tangan dan menjaga jarak serta tidak lupa mengukur suhu sebelum pertemuan dimulai sama halnya dengan protokol kesehatan belajar di sekolah formal (Sipayung et al., 2021). Juga, gereja membagikan hand sanitizer kepada setiap peserta kegitatan. Ini semua dilakukan untuk mencegah hal-hal yang tidak diinginkan.

Pelaksanaan pengabdian masyarakat ini dilaksanakan selama 2 (dua) hari Sabtu - Minggu pada bulan November 2020 dengan persiapan metode kelompok. Dinamika kelompok ini sangat sesuai dengan karakter anak usia Remaja yang di dalamnya semua anggota diharapkan terlibat aktif dan pendamping sebegai fasilitator. Dinamika kelompok membuat setiap invidu peserta didik atau anggota kelompok bisa menyadari siapa dirinya dan siapa orang lain yang berkumpul bersamanya dalam kelompok dengan segala kelebihan dan kekurangannya masing-masing (Susilowati, 2017). Kesadaran seperti ini perlu diciptakan karena kelompok atau organisasi akan menjadi optimal dan efektif apabila memiliki tujuan yang sama atau satu tujuan.

\subsection{Peninjauan ke Lokasi}

Pada tahapan peninjauan lokasi di aula gereja katolik Santo Fransiskus Padang Bulan Medan. pendampingan dan pelatihan ini sangat strategis diberikan kepada para remaja (BIR) di gereja katolik SantoFransiskus Assisi Padang Bulan Medan. Anggota BIR ini masih jarang mendapatkan pengajaran, penyuluhan dan pelatihan dengan metode dinamika kelompok. Jumlah remaja (BIR) sebanyak 66 orang.

\subsection{Pembicaraan dengan Staf Pembina BIR}

Para Pendamping BIR berkesempatan mengembangkan pengetahuannya melalui metode dinamika kelompok yang berdampak pada perkembangan iman mereka dan menyadarkan mereka akan tugas dan fungsi mereka sebagai putera-puteri altar di gereja katolik Santo Fransiskus Assisi Padang Bulan Medan.

Tujuan dari pembicaraan dengan staff Pembina BIR adalah untuk memudahkan pemahaman anggota BIR akan suatu pembelajaran dengan metode dinamika kelompok yang dapat dilakukan berbagai kesempatan sebagai sutau cara atau proses saling kerjasama satu dengan yang lain untuk mencapai suatu tujuan yang sama.

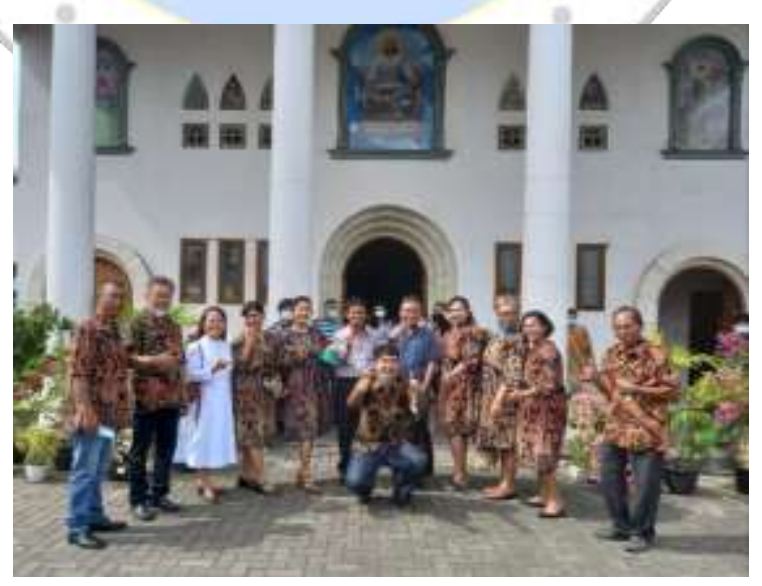

\section{Gambar 1. Pertemuan dengan Staf BIR}

Selain memudahkan pemahaman anggota BIR, pertemuan dengan staf BIR juga memberikan kesempatan kepada para pendamping tentang metode dinamika kelompok sesuai dengan tingkat 
perkembangan para remaja dalam mendampingi mereka akan tugas dan fungsi mereka sebagai puteraputeri altar di gereja Santo Fransiskus Assisi Padang Bulan Medan.

\subsection{Kegiatan}

Setelah kelompok dibentuk, maka beberapa tahapan kegiatan yang dilakukan adalah: Pertama. Interactions (adanya interaksi), terdiri dari 3 (tiga) atau 4 (empat) orang anggota yang ada dalam sebuah kelompok tentunya akan berinteraksi dengan kelompok atau individu lain dalam kelompok tersebut. Hal ini terjadi karena kelompok menciptakan dan mengatur interaksi antar anggotanya. Terdapat dua interaksi dasar dalam sebuah kelompok, yaitu (interaksi hubungan) dan task interaction (interaksi tugas). Interaksi hubungan atau yang lebih dikenal dengan interaksi sosial berkaitan dengan aspek sosial antar anggota kelompok. Sedangkan interaksi tugas merupakan interaksi yang berfokus pada tujuan, tugas, dan proyek kelompok. Dalam interaksi tugas ini, anggota kelompok saling berkoordinasi untuk menyelesaikan suatu tugas atau mencapai suatu tujuan yang sudah ditentukan.

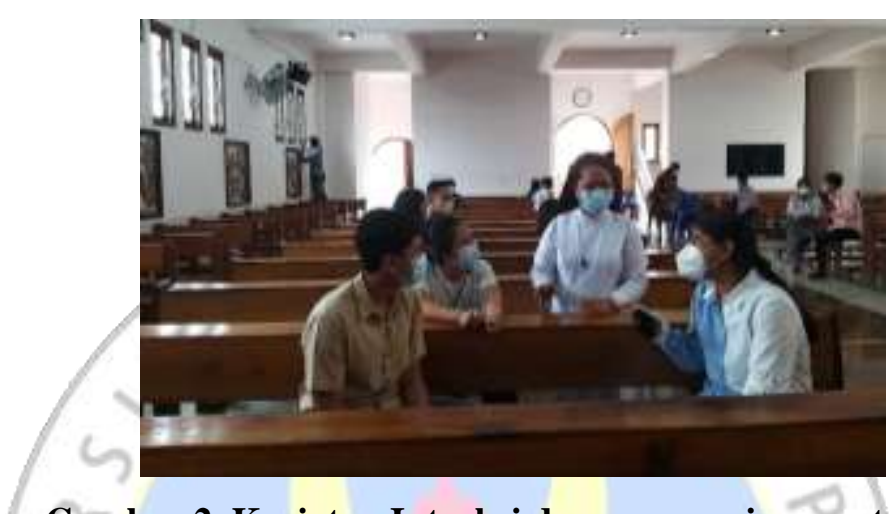

\section{Gambar 2. Kegiatan Inteaksi dengan remaja peserta BIR}

Kedua. Goals (Tujuan), Sebuah kelompok biasanya akan terbentuk karena adanya sebuah tujuan. Kelompok juga memfasilitasi dan mendukung anggota dalam kelompok untuk mencapai tujuan tersebut. Diantaranya terdapat empat tujuan dasar mengapa kelompok terbentuk, yaitu kelompok dibentuk untuk menghasilkan sebuah ide atau gagasan, menentukan solusi terkait suatu hal, menegosiasi solusi terkait dengan konflik, atau melaksanakan suatu tugas tertentu.

Ketiga. Interdependence (Interdependensi), Setiap anggota yang ada dalam sebuah kelompok akan dipengaruhi dan mempengaruhi anggota lainnya, dalam artian saling mempengaruhi sebagaiman hukum kausalitas. Sehingga, akan muncul rasa saling bergantung antar anggota yang satu dengan anggota yang lainnya. Ketergantungan antar anggota ini meliputi pemikiran, perilaku, dan perasaan yang dimiliki oleh seorang individu yang ada dalam kelompok tersebut.

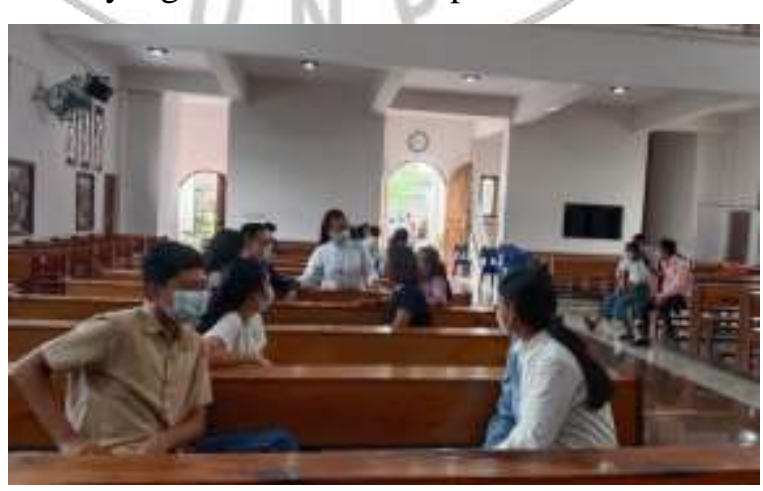

Gambar 3. Interaksi antar anggota kelompok

Keempat. Structure (Struktur); terdapat pattern atau pola yang teratur dalam hubungan yang dimiliki oleh anggota kelompok tersebut. Pola ini terbentuk dari kompleksnya peran, norma, 
hubungan antar anggota yang kemudian membentuk struktur kelompok yang mengatur aktivitas dalam kelompok tersebut serta untuk tercapainya tujuan bersama secara optimal, efektif dan efisien.

Kelima. Unity (Kesatuan), Kelompok merupakan pengaturan sosial yang melekat antara yang satu dengan yang lainnya atau kohesif (Windari, Dewi \& Sihotang, 2020). Oleh karena itu, kelompok juga dapat disebut sebagai sebuah kesatuan yang kuat dari beberapa aspek. Karena biasanya apabila satu bagian saja ada yang gagal dari kelompok ini bisa dianggap gagal semua dan sebaliknya apalagi ada satu bagian dari kelompok ini ada yang sukses atau tujuannya tercapai maka akan merasakan senang semua.

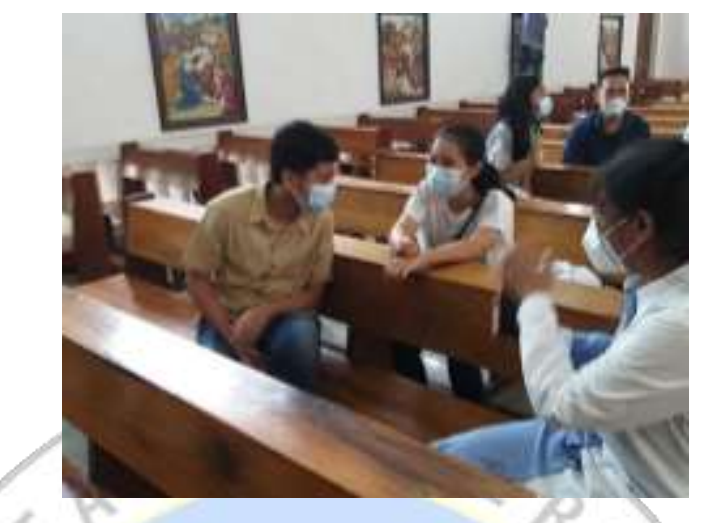

\section{Gambar 4. Anggota kelompok saling menguatkan}

Dengan demikian jelas bahwa dalam dinamika kelompok ada interaksi antar anggota kelompok, ada tujuan yang ingin dicapai, saling mempengaruhi demi tujuan yang sama dan adanya pola tertentu yang sistematis dan akhirnya mencapai kesatuan dan kesepakatan yang akan dilakukan oleh bersama yang terakhir menjadi keberhasilan bersama.

\subsection{Pengolahan Hasil BIR}

Pengolahan data dari hasil penelitian ini selanjutnya diolah secara manual dengan melihat persentasi perkembangan sosial peserta BIR setelah dan sesudah perlakuan dinamika kelompok, selanjutnya di analisa. Analisa data dalam penelitian ini yaitu analisa bivariat. Karena penelitian ini bersifat pra eksperimen dengan pendekatan one group pra-post test design (Lubis et al., 2020), maka dilakukan uji statistic Wicoxon dengan derajat kemaknaan $95 \%(\alpha 0,05)$.

\section{Hasil dan Pembahasan}

Hasil yang diperoleh dari pendampingan ini sangat strategis diberikan kepada anggota BIR di gereja katolik Santo Fransiskus Assisi Padang Bulan Medan adalah:

\subsection{Durasi}

Waktu pelaksanaan pendampingan BIR dilakukan dalam 1 (satu) bulan. Pertemuan dilakukan setiap hari Sabtu dan hari Minggu pukul 15.00 - 16.00 WIB (60 Menit)

\subsection{Capaian}

\subsubsection{Anggota BIR di gereja katolik Santo Fransiskus Assisi Padang Bulan Medan menyadari akan tugas dan fungsi mereka sebagai Putera-Puteri Altar.}

Setiap pembina iman anak perlu menyadari bahwa dirinya dipanggil dan diutus oleh Tuhan untuk mewartakan kabar gembira kepada anak- anak. Tugas dan panggilan tersebut sudah diberikan kepada setiap orang yang menerima baptisan. Tuhan sendirilah yang memanggil, memilih, dan mengutusnya untuk menjalankan tugas itu yaitu mengantarkan anak-anak kepada Tuhan. 


\subsubsection{Anggota BIR di gereja katolik Santo Fransiskus Assisi Padang Bulan Medan masih} jarang menerima pengajaran, penyuluhan dan pelatihan metode dinamika kelompok.

Dalam dinamika kelompok yang dimaksud dalam pengabdian ini bisa dikategorikan dalam kelompok primer, yaitu teman sepermainan (se-usia), satu tujuan. Tujuan yang sama yaitu semua anggota kelompok ingin memahami tugas dan tanggungjawab mereka bergabung dengan BIR tersebut. Sekunder (sosial); bahwa mereka memiliki keterikatan saatu sama lain dan memiliki hubungan emosional karena se iman dan yang lebih dalam spritual juga collective, memiliki struktur atau organisasi yang jelas tapi tidak kaku. Hal ini sejalan dengan pendapat Khusnul dkk (2015:55) bahwa remaja memiliki kebutuhan yang kuat untuk disukai dan diterima kawan sebaya atau kelompok. Sebagai akibatnya, mereka akan merasa senang apabila diterima dan sebaliknya akan merasa sangat tertekan dan cemas apabila dikeluarkan dan diremehkan oleh kawan-kawan sebayanya. Bagi banyak remaja, pandangan kawan-kawan terhadap dirinya merupakan hal yang paling penting. Pengalaman bersama kawan sebaya memiliki pengaruh yang penting bagi perkembangan remaja, pengaruh ini dapat bervariasi, tergantung dari pengukurannya, perumusan hasil yang diperoleh, serta lintasan perkembangan yang dilewati.

3.2.3. Para pendamping berkesempatan mengembangkan pengetahuannya melalui metode dinamika kelompok yang dapat semakin memberikan kesadaran kepada peserta akan tugas dan fungsi mereka sebagai putera-puteri altar.

Kegiatan BIR ini, bukan hanya hal-hal yang rohani saja, akan tetapi ada kegiatan kunjungan ke panti asuhan, ngopi bareng dan berbagai kegiatan yang disesuaikan dengan kondisi remaja. Oleh karena itu pengabdian masyarakat yang dilakukan adalah mendampingi anak-anak BIR agar menyadari Tugas dan Fungsi Mereka sebagai Putera-Puteri Altar dalam gereja katolik. Mereka adalah pelayan-pelayan gereja katolik dalam melayani di altar Tuhan. Hal ini sejalan dengan pendapat Bales yang dikutip Yusliyadi dan Norhadi (2020) mengemukakan kelompok adalah sebuah individu yang berintraksi dengan sesamanya secara face to face atau serangkaian pertemuan. Tiap-tiap anggota saling menerima impresi atau perbedaan persepsi anggota lain dan pada suatu waktu menimbulkan pertanyaan yang membuat semua anggota bereaksi sebagai reaksi sebuah kelompok.

\subsection{Temuan di Lapangan}

Temuan penggunaan metode Dinamika Kelompok di Paroki Santo Fransiskus Asisi Medan dalam meningkatkan Kemampuan Personal Sosial peserta BIR terlihat pada Tabel 1.

Tabel 1. Meningkatkan Kemampuan Personal Sosial peseerta BIR

\begin{tabular}{lcccc}
\hline \multirow{2}{*}{ Sosial Pribadi } & \multicolumn{2}{c}{$\begin{array}{c}\text { Sebelum pendampingan } \\
\text { (dinamika kelompok) }\end{array}$} & \multicolumn{2}{c}{$\begin{array}{c}\text { Sesudah pendampingan } \\
\text { (dinamika kelompok) }\end{array}$} \\
\cline { 2 - 5 } & $\mathrm{n}$ & $\%$ & $\mathrm{n}$ & $\%$ \\
\hline Lebih & 0 & 0 & 4 & 13 \\
\hline Normal & 20 & 67 & 25 & 87 \\
\hline Perhatian & 6 & 20 & 0 & 0 \\
\hline Menunda & 4 & 13 & 0 & 100 \\
\hline Total & 30 & 100 & 30 & \\
\hline $\mathrm{p}$ & & & 0,000 & \\
\hline
\end{tabular}

Berdasarkan tabel 1 terdapat ada pengaruh yang signifikan antara pelaksanaan dinamika kelompok pada peserta Bina Iman Gereja (BIR). Sebelum penampingan BIR melalui dinamika kelompok anak yang mengalami penundaan (untuk memulai komunikasi) sebanyak 13\%. Anak cenderung takut untuk bersosialisasi dan berinteraksi. Namun setelah pelaksaan pendampingan BIR melalui metode dinamika kelompok sifat menunda memulai komunikasi, berinteraksi tidak terjadi sama sekali. 


\subsection{Kelebihan dan Kekurangan}

Di dalam proses dinamika kelompok, tidak selalu lancar dan berjalan baik. Terdapat beberapa faktor yang menghambat maupun faktor yang mendukung atau memperlancar proses dinamika kelompok tersebut.

\subsubsection{Kelebihannya.}

1. Keterbukaan dan kelenturan antar masing- masing anggota kelompok untuk memberi dan menerima informasi dan pendapat anggota yang lain,

2. Kemauan anggota kelompok untuk mendahulukan kepentingan kelompoknya dengan menahan kepentingan pribadi demi, dan

3. Kemampuan secara emosional dalam menerima kaidah atau kesepakatan kelompok.

\subsubsection{Kekurangan}

Membutuhkan waktu yang lama dan tempat tinggal anggota yang berjauhan. Masa pandemic COVID-19 ini yang sangat membatasi gerak setiap orang, sehingga dari beberapa anggota masih enggan untuk berkumpul, namun demikian tetap saja ada di antara mereka yang tetap dating untuk mengikuti kegiatan tersebut karena pihak penyelenggara juga mengikuti protokol kesehatan.

\section{Kesimpulan}

Berdasarkan hasil diskusi dan pembahasan, maka dapat diambil kesimpulan bahwa a) Peserta dapat mengerti maksud yang disampaiakan dalam pelaksaaan pengabdian hal itu dapat dilihat dari antusias para peserta yaitu anggota BIR dan para pendamping BIR, b) Anggota BIR di gereja katolik Santo Fransiskus Assisi Padang Bulan Medan menyadari akan tugas dan fungsi mereka sebagai putera-puteri altar, c) Anggota BIR di gereja katolik Santo Fransiskus Assisi Padang Bulan Medan masih jarang menerima pengajaran, penyuluhan dan pelatihan metode dinamika kelompok, dan d) Para pendamping berkesempatan mengembangkan pengetahuannya melalui metode dinamika kelompok yang dapat semakin memberikan kesadaran kepada peserta akan tugas dan fungsi mereka sebagai putera-puteri altar, e) metode dinamika kelompok secara signifikan mampu meningkatkan kemampuan personal sosial perserta BIR.

\section{Daftar Pustaka}

Fatmawaty, R. (2017). Memahami Psikologi Remaja. Jurnal Reforma, 2(1), 55-65. https://doi.org/https://doi.org/10.30736/rfma.v6i2.33

Hidayati, K. B. (2016). Konsep Diri, Adversity Quotient dan Penyesuaian Diri pada Remaja. Persona:Jurnal Psikologi Indonesia, 5(2), 137-144. https://doi.org/https://doi.org/10.30996/ persona.v5i02.730

Lating, A. D. (2016). Konflik Sosial Remaja Akhir (Studi Psikologi Perkembangan Masyarakat Negeri Maamala Dan Morella Kecamatan Leihitu Kabupaten Maluku Tengah). Jurnal Fikratuna, 8(1), 23-35.

Lubis, R., Dewi, R., Sihotang, D. O., \& Siburian, P. (2020). Urgency of Internal Quality Guarantee System to Improve Higher Education Quality. The 5th Annual International Seminar on Transformative Education and Educational Leadership (AISTEEL 2020).

Marbun, P. (2020). Strategi dan Model Pembinaan Rohani untuk Pendewasaan Iman Jemaat. Jurnal Ilmiah Religiosity Entity Humanity (JIREH), 2(2), 151-169.

Ramos, P., \& Firmanto, A. D. (2017). Bina Iman Remaja dalam Masa Pandemi Covid-19 di Paroki Santa Maria Immaculata Mataram. SAPA-Jurnal Kateketik Dan Pastoral, 6(1), 64-75.

Sipayung, R., Sihotang, D. O., \& Batu, J. L. (2021). Persepsi Guru Terhadap Efektivitas Pembelajaran Online Di Masa Pandemi COVID-19. Jurnal Ilmiah Aquinas, 2(1), 311-321.

Susilowati, E. (2017). Penerapan Dinamika Kelompok Sosial Dalam Meningkatkan Perkembangan Anak Usia Toddler di Posyandu Kelurahan Lirboyo Kediri. Jurnal Ilmu Kesehatan, 6(1), 2631. 
Tibo, P. (2019). Konseling Pastoral Keluarga Sebagai Pendekatan Pastoral Praksis Dalam Mengatasi Problematik Keluarga Katolik Di Paroki Kristus Raja Wolotolo Kevikepan Ende Keuskupan Agung Ende. Jurnal REINHA, 7(1), 59-72.

Wanda, G. F., Telaumbanua, F., \& Era, G. V. (2017). Pola Pemahaman Misdinar Tentang Tugas Dan Fungsinya Dalam Perayaan Ekaristi. Gaudium Vestrum: Jurnal Kateketik Pastoral, 1(2), 98105.

Wetu, H. E. (2017). Pendidikan Karakter Sebagai Bagian Dari Revolusi Mental Menurut Pandangan Gereja Katolik. Pastoral Dan Kateketik, 2(1), 1.

Windari, Dewi, R., \& Sihotang, D. O. (2020). Become a Professional Teacher in the Future. The 5th Annual International Seminar on Transformative Education and Educational Leadership (AISTEEL 2020).

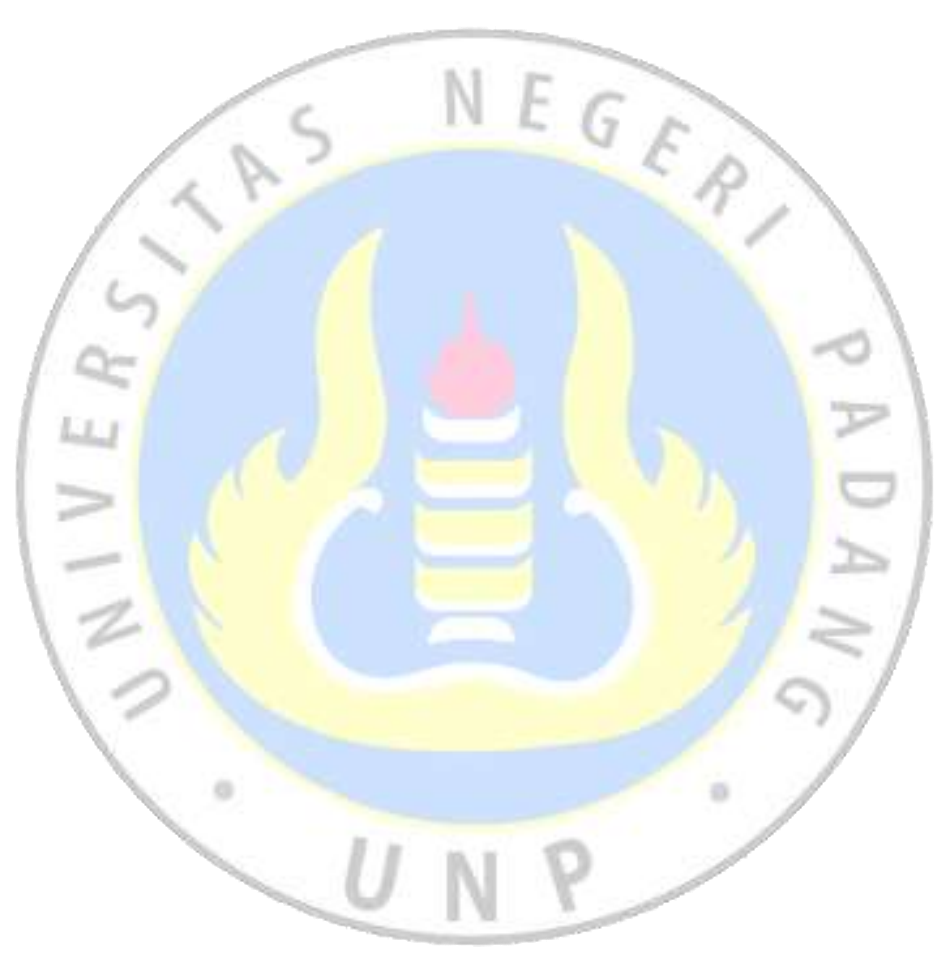

